\title{
Correction to: Abscisic Acid Supplementation Rescues High Fat Diet-Induced Alterations in Hippocampal Inflammation and IRSs Expression
}

\author{
Alberto Ribes-Navarro ${ }^{1}$ Mariam Atef ${ }^{1,2}$. Sandra Sánchez-Sarasúa ${ }^{1}$ • María Teresa Beltrán-Bretones ${ }^{1}$. \\ Francisco Olucha-Bordonau ${ }^{1}$ • Ana María Sánchez-Pérez ${ }^{1}$
}

Published online: 26 February 2019

(C) Springer Science+Business Media, LLC, part of Springer Nature 2019

Correction to: Mol Neurobiol (2019) 56:454-464

https://doi.org/10.1007/s12035-018-1091-z

The author missed to include the second affiliation of Mariam Atef to the original paper published. With this, the authors published this correction.

Publisher's Note Springer Nature remains neutral with regard to jurisdictional claims in published maps and institutional affiliations.

The online version of the original article can be found at https://doi.org/ 10.1007/s12035-018-1091-z

\footnotetext{
Ana María Sánchez-Pérez sanchean@uji.es

1 Department of Medicine, University of Jaume I, Castellón de la Plana, Spain

2 Faculty of Science, Alexandria University, Alexandria, Egypt
} 